\title{
Stratejik Yönetim Süreciyle Örgüt Kültürünün Uyumuna Dair Literatürdeki Tartışmalar
}

\author{
Literature Discussions on the Harmonization of the Organizational Culture with the Strategic \\ Management Process
}

\author{
Murat ÇUBUKCU \\ Doktorant, Uludă̆ Üniversitesi, $S B E$, \\ Işsletme A.B.D., 711314012@ogr.uludag.edu.tr \\ https://orcid.org/0000-0001-9170-4852
}

Makale Başvuru Tarihi: 07.04.2020
Makale Kabul Tarihi: 11.05.2020
Makale Türü: Araştırma Makalesi

$\begin{aligned} & \text { Anahtar } \\ & \text { Kelimeler: }\end{aligned}$
Strateji,
Stratejik Yönetim,
Örgüt Kültürü,
Uyumlama,

Uyumlama,

\section{ÖZET}

Örgüt kültürleri ile stratejilerinin uyumlaştırılmış olması ve stratejileri en iyi uygulayan örgütlerin performanslarında olumlu fark yaratabildikleri, yazında üzerinde önemle durulan konulardır. Bu çalışma, örgütsel kültürün stratejik yönetim süreci ile uyumunun ve etkileşiminin önemi üzerine literatürdeki tartışmalara odaklanmaktadır. Işsletmelerdeki stratejik yönetim süreci ve örgüt kültürünün uyumu hakkındaki tartıșmaları tespit etmek ve aynı zamanda ilgili alan yazınına anlamlı bir katkı sunmak amaçlanmıștır. Bu amaçla, işletmelerde uygulanan stratejik yönetim süreci ile örgüt kültürünün uyumunun önemi, literatürdeki tartışmalar ışı̆̆ında sunulmuş̧ur. İçerik analizi yapılarak anlam kazandırılması amacıyla kitaplardan ve makalelerden elde edilen bilgiler, elde edildiği şekilde alıntılar yapılarak kullanılmıştır. Makalemizde konu ile ilgili kaynaklar gözden geçirilmiş, çeşitli görüş ve tutumlara yer verilmiştir. Yapılan literatür taraması sonucunda, stratejik yönetim süreci ile örgüt kültürünün uyumlaștırılması konusunun önemli bir tartışma alanı olduğu görülmüştür. Makalemizde konu hakkındaki literatürdeki tartışmalar ortaya konulmuştur. Sürdürülebilir rekabet avantajı sağlanmasında, strateji ile örgüt kültürü̈nün uyumlaștırllması önemli bir kritik başarı faktörüdür. Literatürde stratejilerle örgüt kültürünün olumlu etkileşimi ve uyumun işletme performansına katkı sağladı̆̆ı yönündeki görüşlerin ă̆ırlıklı olduğu tespit edilmişstir.

\section{ABSTRACT}

Organizational cultures and strategies that have been able to harmonize their strategies and make a positive difference in the performances of organizations that best implement their strategies are important issues in the literature. This study focuses on the discussions in the literature on the importance of the harmony and interaction of the organizational culture with the strategic management process. This study focuses on the discussions in the literature on the importance of the harmony and interaction of the organizational culture with the strategic management process. For this purpose, the importance of the harmony of the organizational culture and the strategic management process applied in the enterprises has been presented in the light of the discussions in the literature. In order to give meaning by making content analysis, obtained information from books and articles were cited and also used as quoted. In our article, the resources related to the subject were reviewed and various opinions and attitudes were included. As a result of the literature review, it was seen that the issue of harmonization of organizational culture with the strategic management process is an important discussion area. In our article, the discussions on the subject in the literature are presented. Harmonization of strategy and organizational culture is an important critical success factor in achieving sustainable competitive advantage. In the literature, it has been determined that the positive interaction of strategies and organizational culture and that the harmony contributes to the performance of the company.
\end{abstract}

Keywords: 


\section{GíRIŞ}

Stratejik yönetim sürecinde, uygun örgüt yapısının seçilmesi veya seçilen stratejilere uygun örgüt yapısının oluşturulması kadar stratejilere uygun örgüt kültürünün oluşturulması konuları da literatürde kritik başarı faktörleri olarak konu edinmiştir. Bu çalışmanın amacı, işletmelerde stratejik yönetim süreci uygulamalarının örgüt kültürüyle uyumunun önemi konusunda yapılan tartışmaların literatür ve bu konudaki mevcut tartışmalar çerçevesinde yönünün kuramsal olarak ortaya konulmasının sağlanmasıdır. Bu çerçevede çalışmamızda literatür incelemesi yapılmış ve konuyla ilgili mevcut çalışmalardan alıntılar yapılarak tartışmalar ortaya konulmuştur. Çalışmamızda örgüt kültürü, kurum kültürü ve işletme kültürü aynı anlamda işletmelerin kültürünü ifade etmek amacıyla kullanılmıştır. Örgüt işletmeye göre daha geniş bir kavramı ifade eder. Bu çalışmamızda yerine göre her üç kavramda birbirine benzer kavramlar olarak kullanılacaktır. Ancak çoğunlukla örgüt kültürü kavramı kullanılmıştır.

Stratejik yönetim alanında, stratejilerin belirlenmesinde dikkate alınması gereken en önemli etkenler olarak örgütün yapısı, süreçleri ve örgütün kültürü daha yoğun üzerinde durulmuş konulardır. Örgüt kültürü örgütlerin sürdürülebilir rekabet avantajı kazanmalarında kritik bir rol oynamaktadır. İşletmeler uyguladıkları stratejilerini, örgüt kültürleri ile uyumlaştırmanın öneminin farkına varmışlardır (Akgemci ve Güleş, 2010:6). Kültür örgütün içsel çevresini ifade eder. Stratejilere uygun nitelikte örgüt kültürünün oluşturulması konuları, stratejik yönetim yazınında üzerinde tartışmalar yapılmış önemli konulardır.

1960'lı yıllarda örgütsel kültür, örgütsel gelişim hareketi ve örgütsel değerlerin insancıl anlayışı ile ilgiliydi ve örgütsel gelişim için bir araç olarak algılanıyordu, ancak bunun rekabet avantajı olarak değerlendirilmesine çok az ilgi vardı. Ancak 1980'lerde Japon işletmelerinin çalışması ekonomik ve örgütsel alanda örgüt kültürünün önemini gösterdiğinde, örgüt kültürü onu yönetim stratejisine ve rekabet edebilirlik değişkenine dönüştürmek amacıyla büyük ölçüde pragmatik olarak ele alınmaya başlandı. Bourantas vd.'nin (1990) ifade ettiği gibi, 1980'ler örgütsel teoride yeni modellerin ortaya çıkması ve değerlerin, inançların, ritüellerin, geleneklerin ve diğer değişkenlerin örgütsel performans üzerindeki etkisini araştıran diğer stratejik tasarımlarla karakterize edildi. 1990'ların ortalarında örgüt kültürü, Schein (1992)'e göre somut olmayan bir organizasyon varlığı olarak anlaşılmaya başlandı ve bir organizasyonun liderliği tanım ve içselleştirmede merkezi bir rol üstlenerek yönetim değişkeninden daha stratejik hale geldi. Bu dönemde Igo ve Skitmore (2006), amacı örgüt kültürü tipolojilerini tanımlamak olan çeşitli araç ve yöntemleri tanımlamıştır (Russo vd., 2013:13-14).

Literatürde Naor vd. (2008) gibi akademisyenlerin ve uygulayıcıların operasyon yönetimi uygulamalarını yerine getirirken örgütsel kültürü anlamanın önemini giderek daha fazla kabul ettikleri görülmektedir (Naor vd., 2008:671). Bijlsma-Frankema (2001), Cartwright ve Schoenberg (2006), Lodorfos ve Boateng (2006), Nguyen ve Kleiner (2003) gibi araştırmacılar kültürel uyumsuzluğun, düşük başarı oranlarındaki en önemli nedenlerden biri olduğunu tespit etmişlerdir. Chatterjee vd. (1992) örgütsel kültürün neredeyse tüm örgütsel uygulamalar, direktifler, liderlik tarzları ve yönetim süreçleri üzerindeki etkisinden kaynaklandığını belirtmektedirler. Teerikangas ve Very (2006) ve bir meta-analitik çalışmada Stahl ve Voigt (2008) çalışmalarında görüldüğü gibi literatür taramasında, ulusal kültürdeki farklılıkların örgütsel düzeyde kültürel farklılıklardan çok sosyokültürel entegrasyon, sinerji gerçekleşmesi ve hissedar değeri üzerinde daha az olumsuz bir etkiye sahip olduğunu bulmuşlardır (Bauer ve Matzler, 2014:273).

Örgüt kültürü stratejilerin uygulanmasında kritik öneme sahiptir ve bir süzgeç, standardize etme ve değişim rehberi olma aracı olarak stratejik bir öneme sahiptir. İşletmeler çalışanlarına, katkılarının değerli olduğunu söyleyebilecek ve uzmanlıklarının önemli olduğu noktalarda karar alma süreçlerine katılımı sağlayacak örgüt kültürüne sahip olmalıdır (Maciariello ve Drucker, 2005:61). Başarılı bir strateji uygulamasının en önemli yönetsel bileşenlerinden biri stratejiye uygun kurum kültürünün şekillendirilerek ortak değerler oluşturulması ve stratejik liderlik gösterilmesidir (Thompson ve Strickland, 1993:219). Bu nedenle çalışmamızda bir örgütün üyeleri tarafindan paylaşılan inançlar, değerler ve varsayımlar olarak tanımlanan kültürün örgütsel boyutuna odaklaniyoruz.

Çalışmamızda öncelikle literatür taraması ile stratejik yönetim süreci uygulamaları ile örgüt kültürünün karşılıklı etkileşimi ve uyumunun önemi üzerine yapılan yazındaki tartışmaların açıklanması amaçlanmıştır. Konu ile ilgili kaynakların gözden geçirilmesi, görüşler ve betimlemelerin bulunması sağlanmıştır. Bu amaçla stratejik yönetim yazınındaki, stratejik yönetim ve örgüt kültürü ilişkisi üzerine literatürdeki tartışmalar ortaya konulmuştur. Örgüt kültürünün özellikleri ve değişim süreci ele alınmış ve stratejik yönetim aracı olarak örgüt kültürü ve uyumunun önemi açıklanmıştır. Sonuç bölümünde ise, literatürdeki tartışmaların ortaya konulmasına yönelik genel bir değerlendirme yapılmıştır. Literatürde strateji ile örgüt kültürü arasında uyumun mevcudiyeti ve karşılıklı etkileşim olduğunun yaygın kabul edilmiş görüşler olduğu tespit edilmiştir. 


\section{2. ÖRGÜT KÜLTÜRÜ KAVRAMI VE UNSURLARI}

Örgüt yapısı planlı bir ağ ve süreçtir. Bu yapı içerisinde fikir, inanç ve değerleri yansıtan örgüt kültürüdür. Bu süreçte örgüt üyeleri, dış bağlılıktan değer ve inançları beraberinde getirir (Hall ve Saias, 1980:152). Örgüt kültürü kavramı ile kurum kültürü ve işletme kültürü kavramlarının zaman zaman eş anlamlı olarak kullanıldığı görülmektedir. Literatürde örgüt kültürü farklı açılardan ele alınmış ve örgüt kültürünün çok çeşitli tanımlamaları yapılmıştır. Stephan R. Roddins, "örgüt kültürünü tanımlayamam ancak gördüğüm zaman ne olduğunu anlarım", demiștir (Özkalp, 1999:438). Örgüt kültürü kavramı, büyük ölçüde Schein (1990)'ın değerler, normlar ve eserler içeren üç katmanlı örgüt kültürü modelinden oluşur. Khazanchi vd. (2007)'e göre işletmenin değerleri işletmenin temellerini oluşturur. Görünür değiller, ama çok etkilidirler ve örgütlerin ideolojisine ve felsefesine dayanırlar. Hogan ve Coote (2014)'e göre değerler, davranışsal beklentiler ve davranışlar olan örgütsel normları çerçevelemektedir. Örgütsel değerler, örgütsel üyelerin davranış ve algılarında kendini gösterir (Hock vd., 2015:436).

Schein (1985) ve Louis (1986)'a göre her grubun, kurumsal veya başka bir şekilde üyelerinin ortak geçmişi ve deneyimleriyle şekillenen benzersiz bir kültürü vardır. Genel olarak ifade etmek gerekirse kültür, bir gruptaki insanların birbirleriyle etkileşim kurma biçimlerinin hemen hemen tüm yönlerini etkiler. Lorsch (1986), Donaldson ve Lorsch (1983), Bhagat ve McQuaid (1982), Schwartz ve Davis (1981) gibi araştırmacılara göre; üst yönetim düzeyinde kültür, davranış kuralları, liderlik stilleri, idari prosedürler ve çevrenin algılanması gibi örgütsel uygulamaları etkiler (Chatterjee vd., 1992:320).

Kültür, bireylerin bir kuruluşta maruz kaldıkları inançları, bilgileri, zihin tutumlarını ve geleneklerini oluşturur; bunun sonucunda dil, değer, davranış ve düşünce alışkanlıkları kazanılır (Hall, 1992:139). Kültür, işletmelere rekabetçi tehditleri karşılamaya ve değişen ekonomik ve sosyal çevreye adapte olmaya yol gösterir. Kültür, bir işletmenin faaliyetleri, görüş ve eylemleri için bir model olarak saldırganlık, savunuculuk, çeviklik gibi değerleri ima eder. Bu model çalışanlara telkin edilir ve sonraki nesillere aktarılır. CEO'ların sadece sözleri kültürü üretmez, bilakis onun eylemleri ve yöneticileri de etki eder. Bir örgütün kültürü onun stratejisi ile tutarlı olduğunda onun en büyük gücü olabilir (Thompson ve Strickland, 1984:341).

Örgüt ya da kurum kültürü Kotter ve Heskett (1992) tarafından önerildiği gibi iki seviyeye sahiptir. Daha az görünür düzey, kuruluş üyeleri tarafindan paylaşılan değerleri içerir; bu tür bir kültür, grup üyeliği değişse bile, grup davranışını şekillendirme eğilimindedir ve zaman içinde devam eder. Öte yandan, daha güçlü bir işletme kültürü, etik güçleri ve nitelikleri ile bir örgütün davranış modelini veya stilini özetler (Smimou, 2020:361).

Lindsey (2011)'e göre CEO konumlandırması ile uyumlu ve mevcudiyetine cevap veren bir örgüt kültürü, organizasyon yapısının yorumlarıyla oluşur ve bir organizasyonun üyeleri arasında çalışma ortamıyla ilgili ortak anlamlar içerir. CEO ve örgüt kültürü arasında dinamik bir ilişki vardır (Prince vd., 2019:63). Zukin ve DiMaggio (1990)'a göre işletmelerin yerleşik olduğu sosyal içerik yapısal, bilişsel, kurumsal ve kültürel olarak sınıflandırılabilen bir dizi unsurdan oluşmaktadır (Gulati vd., 2000:204). Örgüt kültürü, örgütü diğerlerinden farklı kılan belirli değerler sistemidir (Greenberg, 2002:308). Güçlü örgüt kültürleri, grup düşüncesi, dar görüşlülük ve kendini beğenmişlik gibi problemlerle karşılaşılabilir (Marcouse vd, 2014:108). Stratejilerin uygulanması aşamasında, örgüt kültürünün oluşturulması önemli bir konudur. Paylaşılan ortak değerler, ilkeler sistemi olan kültür, strateji uygulaması ile uyumlaştırmayı gerektirir (Hill vd., 2013:397).

Örgüt kültürü Barney (1986), Schein (2004), Engelen vd. (2014) tarafından bireylerin bir kuruluş içinde paylaştıkları ve işlerini yürütmek için nasıl davranmaları gerektiğini belirleyen ortak değerler, normlar, inançlar ve varsayımlar olarak kabul edilmiştir. Barney (1986) ve Engelen (2010) gibi önceki çalışmalar örgütsel kültürün karmaşık ve öznel doğasının altını çizmiştir. Riratanaphong (2014)'e göre örgüt kültürü, bir örgüt içindeki bireylerin ve grupların davranışlarını güçlü bir şekilde etkileyen normlar üreten inançlar ve beklentilerle ilgilidir. Schein (2004)'e göre örgütsel kültür, işletme performansında yaygın bir rol oynar çünkü bireylerin sorunları başarılı bir şekilde nasıl çözeceklerini toplu olarak öğrenmek için kullanmaları gerektiği belirtilmektedir. Bu anlamda örgütsel kültür, Barney (1986)'e göre üstün işletme performansı için çok önemli kabul edilebilir (Khedhaouria vd., 2020:2-3).

Literatürde ve uygulamada en çok rastlanılan, örgüte bağlılığını artıran semboller, ritüeller gibi örgüt kültürü mekanizmalarını şu şekilde özetleyebiliriz; örgüt logoları, bayrakları, ticari unvanları, kıyafetleri ve fiziki yapıları akılda kalabilecek semboller, örgüt hayatında yazışma şekilleri, konuşma tarzı, ödüller, yıldönümleri, planlı işletme gezileri ve emekliliğe ayrılanlar için verilen yemekler, örgüt içinde yapılan selamlaşmalar, sloganlar, jest ve mimikler örgütlerin ayırıcı özelliğini ortaya koyan unsur ve mekanizmalar olarak göze çarpmaktadır. Deshpande ve Webster (1989)'a göre örgütsel kültür, bireylerin örgütsel işleyişini anlamalarına 
Uluslararası Yönetim Akademisi Dergisi, 2020, C.3, S.1, ss.138-151 yardımcı olan ortak değerler ve inanç kalıpları ile ilgilenir ve böylece işletmede davranış normları sağlar (Appiah-Adu ve Blankson, 1998:240). Chatterjee vd. (1992)'e göre örgütsel kültür, örgütsel uygulamaları, direktifleri, liderlik tarzlarını ve idari süreçleri etkilemektedir (Bauer ve Matzler, 2014:274).

Stratejik yönetim düşüncesinde vizyon, misyon, değerler, örgüt kültürü gibi görünmeyen ama işletmenin inanç sisteminin felsefesini oluşturarak yön veren ve böylece fark yaratan önemli bir boyut olarak kabul edilmektedir. McKinsey " $7 S$ " çerçevesi olarak meşhur olan yaklaşımında odaklanılması gereken faktörler olarak; strateji, yapı, sistem, stil, ortak değerler, çalışanlar ve kabiliyetler biçiminde sıralamıştır. Peters ve Waterman (1982) örgütsel kültürün başarı için en önemli faktör olduğunu ileri sürmüşlerdir. Batı yönelimli yönetim daha çok kaba S'lere (yapı, sistem ve strateji) vurgu yaparken, Amerikan ve Japon işletmeleri ise yumuşak S'lere, özellikle de ortak değerlere vurgu yapmaktadırlar (Barca, 2005:17).

Uygulanan stratejilerin başarıya ulaşmasında örgüt kültürünün önemli etkileri vardır (Schein, 1984:3). Strateji, yapı, süreç ve kültürün tümü merkezi bir hedefle şekillenir veya odaklanır ve bu nedenle birbirini tamamlar (Miller, 1996:509). Stratejilerin uygulamaya konulmasında, örgüt kültürü tesirini gösterir. Örgüt kültürü stratejilerin örgütte benimsenebilmesini kolaylaştırabileceği gibi zorlaştırabilirde (Johnson ve Scholes, 1999:247). Literatürde örgüt kültürünün unsurları olarak genellikle değerler, davranışlar, normlar, törenler, gelenekler vb. gibi olguların ele alındığı görülmektedir (Unutkan, 1995:45-46).

Stratejik bir zihniyet için, stratejinin, herkesin işi olduğuna dair ortak bir inanç oluşturulmalı. Bu stratejik olarak düşünmek anlamına gelir ve belirli bir kültür, bir dizi ortak değer ve kabul edilen davranış gerektirir (Fogg, 2012:80). Örgütün yapısı da planlı bir ağ ve aynı zamanda süreçtir. Bu sürecin sonucu fikir, inanç ve değerleri yansıtan örgütün kültürüdür. Bu süreçte örgüt üyeleri, dış bağl1lıktan değer ve inançları beraberinde getirir. Her örgüt, tedarikçilerinin, müşterilerinin, rakiplerin ve hükümetin iş birliğine gereksinim duyan bir yapıdır. Yapı aynı zamanda, güç ve bağımlılık ilişkilerini tanımlayan siyasi bir hiyerarşidir. Bu hiyerarşi, kökenleri dışsal olsa dahi, içselleştirilmelidir ve böylece örgüt yapısının bir parçası haline gelir (Hall ve Saias, 1980:152).

Literatürde örgüt kültürünün unsurları olarak genellikle değerler, davranışlar, normlar, törenler, gelenekler vb. gibi olguların ele alındığı görülmektedir (Unutkan, 1995:45-46). Bir örgütün politikaları, uygulamaları, gelenekleri, felsefi inançları birleştirici veya ayırt edici bir kültürünü oluşturur. Bir işletmenin stratejik eylemleri, onun kültürel özelliklerini ve yönetsel değerlerini yansıtır. Bir işletmenin değerleri ve kültürü, bazen stratejik hamlelerin dikkate alınması veya reddedilmesinde baskın rol alır. Hatta bazı durumlarda bir işletmenin temel inançları ve kültürü stratejik hamlelerin seçimine bile hâkim olur (Thompson ve Strickland, 1993:46). Örgütün sahip olmuş olduğu kültür, örgüt üyeleri arasındaki benzerlikleri öne çıkarmalı ve örgüt yapısının unsurları ile uyumlu olmalıdır. Örgüt üyeleri arasındaki çeşitlilikten yararlanma fırsatından kaçınılmamalıdır. Farkl11ıklar örgütün zenginliğini yansıtır (Clayton, 2002:235).

\section{3. ÖRGÜTLERDE DEĞİŞIIM VE DÖNÜŞÜM KÜLTÜRÜNÜN OLUŞTURULMASI}

İşletmelerin faaliyetlerini sürdürebilmeleri, sürdürülebilir rekabet avantajı sağlayabilmeleri için değişim ve dönüşümlere, stratejilerini ve/veya yapılarını değiştirerek ayak uydurmaları, hızla uyum sağlayabilmeleri gerekmektedir (Burton ve Obel, 2004:2). Günümüzün rekabetçi iş ortamında birçok kuruluşun ya kilit iş sonuçlarını iyileştirmenin ya da diğer örgütsel değişim çabalarının kültürel engellerini aşmanın bir yolu olarak planlı kültürel değişim girişimlerine katılmaya motive olması şaşırtıcı değildir (Gover vd., 2016:567).

Uyum perspektifine bağlı olan Child (1972), Pfeffer ve Salancik (1978) gibi bilim adamları, işletme ve çevresi arasında bir uyum sağlama görevinin üst yönetime ait olduğunu savunmuşlardır. Bu nedenle, Andrews (1971), Hambrick ve Mason (1984), işletmenin stratejik liderleri olarak üst düzey yöneticilerin, kuruluşla ve strateji politikalarıyla ilgili gelişmeler için dış çevreyi izledikleri ve gerektiğinde ayarlamaya başladıklarını varsaymışlardır. Bu görüşte örtük olan, üst düzey aktörlerin, değişen süreklilikleri karşılamak için gerektiğinde örgütsel değişim ve yeniden yönlendirme yapmaya hazır, uyanık ve uyarlanabilir bir duruş sergilemesidir (Geletkanycz, 1997:615). Geletkanycz (1997) çalışmasının bulgularının uygulayıcılar için belki de en önemli sonuçları, farklı kültürel geçmişlere sahip yöneticilerin değişime eşit derecede açık olmadığını göstermesidir (Geletkanycz, 1997:631).

Kültür aktif yaşayan bir olgudur (Morgan, 1998:162). Literatürde stratejideki değişim ve yeniden yapılandırma konularında yapılan tartışmalara ve çalışmalara özellikle son yıllarda sıklıkla rastlanmaktadır. Örgüt kültürü, bir grubun dışsal adaptasyon yâda içsel bütünleşmeden kaynaklanan sorunlarını çözme esnasında öğrendiği, paylaşılmış ve geçerliliği kanıtlanmış olan, yeni örgüt üyelerine ise düşünmenin, hissetmenin ve algılamanın doğru yolu olarak öğretilmekte olan temel varsayımlardır (Schein, 1984:3). Örgüt kültürü, örgüt üyelerinin 
davranışlarını etkiler ve yönlendirir. Stratejilerle uyumlu güçlü örgüt kültürü, doğru insan kaynağının seçilmesini ve istenilen şekilde yönlendirilmesini kolaylaştırır (Grant ve Jordan, 2014:444).

Literatürde örgüt kültürü değişimi üzerine yapılan araştırmalarda iki bulgu dikkat çekmektedir. Birincisi, Harris ve Metallinos (2002) gibi mevcut çalışmalar, çalışanların neden örgütün planlanan kültürel değişimi üstlenmeye karar verdiklerine bağlı olarak değiştiğini ortaya koymuştur. İkincisi, literatürün gözden geçirilmesi, bölgedeki ampirik araştırmaların genellikle planlanan değişim çabalarının aslında bir şekilde kurumun kültürünü değiştirdiği varsayımına dayandığını belirledi. Örneğin, Ogbonna ve Wilson (2003) çalışması, çalışanların davranışları değişirken değerlerinin değişmediğini ve Harris ve Ogbonna'nın (2002) çalışması, kültürel değişimin bir süreklilik içinde gerçekleştiğini (daha küçük veya daha büyük boyutlarda istenen değişikliklerin meydana geldiğini) bildirmiştir (Gover vd., 2016:569).

İşletmeler, yüksek potansiyelli çalışanlarını elde tutmayı ve motive etmeyi, kurumun kültürünü ve ondan ortaya çıkan yapısal modeli güçlendirmeyi ve hedeflerini mümkün olan en düşük maliyetle gerçekleştirmeyi amaçlamalıdır (Russo vd., 2013:16). İşletme içinde gerçekleşen etkileşim ve öğrenme sayesinde çalışanların davranışları koşullandırma yoluyla yönlendirilir ve koşullandırma kurum kültürü ile etkileşim yoluyla gerçekleşir (Smimou, 2020:363). Kültürdeki değişiklikleri ve kültürler arasındaki farklılıkların anlaşılması, bir ağın yada örgütün rekabet avantajı kazanma yeteneği üzerinde önemli bir etkiye sahip olabilir. Bir ağın veya örgütün faaliyet gösterdiği ekonomik sistem, genel ortamın yasal ve politik boyutları, yasaların ve işin yasal sistemin, hükümet ve iş arasındaki ilişkinin genel yapısı ile birlikte etkilidir (Hittmar ve Jankal, 2015:14).

Literatürde genellikle örgütsel değişim süreci ile örgütsel öğrenme süreçlerinin ilişkilendirildiği görülmektedir. Öğrenme Okulu temsilcilerinden Lindblom ve Mintzberg'e göre strateji sadece bir bir plan değil, öğrenme sürecini de barındıran bir karar dizisidir (Barca, 2005:25). Öğrenen bir organizasyonun, ana karakteristiklerinden biri, güçlü bir organizasyon kültürü, değişim ve uyumu teşvik etmesidir. Öğrenen organizasyon kültürü, açıklığı, sınırsızlığı, eşitliği, sürekli gelişmeyi ve risk almayı teşvik eder. Kültürel değerler, değişen bir diş çevre ile sağlıklı uyumu teşvik eder (Daft, 2004:371-372).

Değişim sürecinde örgüt kültürünü anlayıp kavramak değişimi kolaylaştırır. Tüm çalışanların bu değişim sürecinde gönüllü katılımını sağlayarak örgütsel iklimin oluşturulması önemlidir. Olumlu bir örgütsel iklim, yeni fikirlerin ve firsatların başarılı bir şekilde adapte edilmesinde ve uygulanmasında çok önemli bir faktördür. Gerçek bir stratejik esneklik üretir ve uzun vadeli bir perspektifi, ortak problem çözme düzenlemelerini, bilgi transferini, korumayı ve çevresel değişimlere uyum sağlamayı teşvik eder (Perez vd., 2014:860).

Kanter (1983) gibi bazı araştırmacılar, gelecekte üst yönetimin temel görevinin, değişim üzerine gelişen örgüt kültürlerinin desteklenmesi olacağını savunmuşlardır (Hall, 1992:139). Johns (2006:396), Hofstede'nin (1980, 2001) ampirik çalışmalarına dayanarak, ulusal kültürün örgüt kültürlerindeki değişimi kısıtladığını açıkça belirtmiştir (Gerhart, 2009:242). Kotter ve Heskitt (1992), Schein (2004) ve Prince vd. (2019)'nin yaptıkları vaka analizleri, CEO'ların bir örgütün kültürünü oluşturma, sürdürme ve değiştirme konusunda önemli bir rol oynadıkları tezini desteklemiştir. Ayrıca, belirli CEO rol davranışları örgüt kültürünü şekillendirir ve örgütün kültürüne çeşitli şekillerde rehberlik eder (Prince vd., 2019:66).

Doz ve Kosonen (2010)'e göre hızla değişen çevrede, örgütlerin sürekli değişen talepleri karşılamak için stratejilerini sürekli olarak ayarlaması ve yenilemesi gerekir. Strateji uygulamaları, özellikle resmi örgüt yapılarında sık sık değişiklik yapılmasını gerektirdiğinden zorlayıcıdır. Battilana ve Casciaro (2012), Kleinbaum ve Stuart (2014) ve Vogel (2005) gibi araştırmacıların değişim hakkındaki son çalışmaları da benzer şekilde, örgütlerin resmi yapılarını değiştirdiklerinde bu durumun örgüt içini de etkileyeceğini belirtmişlerdir (Lynch ve Mors, 2018:1-2).

Stratejik yönetim düşüncesinin özünde, işletme içi yenilikçilik kapasitesinin artırılması, bilginin yönetilmesi, entelektüel sermayenin aktifleştirilmesi, yenilikçi örgüt kültürünün oluşturulması gibi yönetsel beceri ve bütün bunları destekleyecek örgütsel yapı ve sistemleri yatmaktadır (Barca, 2009:48). Örgütler değişim sürecinde, stratejiler arasında en uygununun seçilmesinin yanısıra, örgüt kültürüne uygunlukla birlikte, örgüt-çevre arasındaki uyuma da önem verilmelidir (Ekşi, 2009:169).

Değişim her zaman arzu edilen ve olumlu bir şey olarak algılanamadığı için, genellikle daha fazla ya da yeni kaynakların seferber edilmesini gerektirmekte, sosyal ve finansal maliyetlerde artışa neden olmaktadır. Değişim örgüt içi ve dışı geniş sonuçlar doğurabilir. Sürekli değişen iş ortamında, değişen ve birbirine bağlı iş ortamındaki uyum, yeteneklerini geliştirmenin yollarını sunar (Fonfara vd., 2018:1-4). Örgüt ve çevresi arasında karş1ıklı etkileşim vardır. Modern yönetim teorisi olan sistem ve durumsallık teorileri, örgütleri çevreleri ile ilişkili açık sistemler olarak ele alır (Mondy ve Gordon, 1990:630). Çevre stratejisinin başarılı olabilmesi için, 

işletmenin bütün çalışanlarının gerçekten bu stratejiye inanıyor olması gerekir. Bu da örgüt kültüründe bir değişim anlamına gelecektir. Dolayısıyla yönetime önemli bir görev düşmektedir (Nemli, 2000:107).

Örgütün sahip olmuş olduğu kültür kolay bir şekilde değiştirilemez. Örgütteki bireylerin tutum ve davranışlarını bir anda değiştirmesi çok zordur. Zaman ve çaba ister. Dolayisıyla örgüt kültürünün, seçilen ve uygulanan strateji ile uyum içerisinde olması, dinamik bir çevrede faaliyet gösteren işletmeler için, daha da önemli hale gelmiştir (Dursun, 2013:50). Örgütsel değiş̧im stratejik değişimden daha yavaştır. Bir örgüt yapısından diğerine geçiş anlık bir süreç değil, özellikle büyük işletmelerde uzun yıllar süren bir süreçtir (Cortes vd., 2012:995).

Örgüt kültürü geçmişi ve çevresel değişimleri yansıtır, örgüt kültürü, işletmelerin stratejik eylemlerini kolaylaştırabilir de engelleyebilir de. Örgüt kültürünün gelişiminde, dönüşümcü liderlerin etkisi, inanç ve değerler, kurucuların görüşlerinin etkisi vardır. Geçerli örgüt kültürü, çevresel değişimlere uyum gösterebilmeli (Charles, 1992:190). Değişim ve değişime direnç kaçınılmaz olduğundan, bu iki durumla başa çıkmak için çeşitli teknikler geliştirilmelidir. Bunu başarmanın bir yolu olarak, yeni fikirlerin, yönetimin yararına olduğu kadar astların da yararına olduğunun çalışanlara açıklanmasıdır (Hodgetts, 1997:269). Akademisyenler kültür değişiminin başarısının büyük ölçüde çalışanların değişime verdiği desteğe dayandığını belirlemişlerdir (Gover vd., 2016:580).

\section{STRATEJİ ÖRGÜT KÜLTÜRÜ UYUMU KONUSUNDA LITERATÜRDEKİ TARTIŞMALAR}

Örgütler, çevreyle karşılıklı iletişim ve etkileşim içerisinde bulunan sosyal varlıklardır. Bu çerçevede örgütler, sürekli değişen ve gelişen iç ve dış çevreye uyum sağlayarak birtakım değerler çerçevesinde çalışmak zorundadırlar (Özdevecioğlu, 1995:120). Kültür yapısı, sistemleri ve çalışanları stratejisi için tamamen uygun olan hiçbir örgüt yoktur (Davis, 1982:68). Strateji, yap1, süreç ve kültürün tümü merkezi bir hedefle şekillenir veya odaklanır ve bu nedenle birbirini tamamlar (Miller, 1996:509). Davis'e (1982) göre, kültür yapıs1, sistemleri ve çalışanları stratejisi için tamamen uygun olan hiçbir örgüt yoktur (Davis, 1982:68). Başarılı bir strateji, çevre ile iyi uyum sağlayan bir strateji olacaktır (Hittmar ve Jankal, 2015:12). Örgüt kültürüne hâkim kutsal yâda değişmez parçalarla uyumlu bir strateji seçmek, strateji yapıcıların sorumluluğundadır. Strateji uygulayıcıların görevi, seçilen stratejiyi, örgüt kültürü ile yakın hizaya getirmek ve orada tutmaktır. Strateji ile kültürü uyumlama güçlü bir meydan okuma sunar (Thompson ve Strickland, 1993:255). Örgütün uyumu, örgütsel esnekliği ve değişen çevreye uyarlanabilirliği yansıtmalıdır (Aleksic ve Jelavic, 2017:88).

Literatürde farklı araştırmacılar tarafından örgütsel kültür konusunun farklı şekillerde ele alındığı görülmektedir. Handy (1980)'e göre, farklı kültürler çok farklı yönetim tarzları, yapıları, prosedürleri ve ödül sistemleri üretirler (Russo vd., 2013:14). Nahavandi ve Malekzadeh (1988), Jemison ve Sitkin (1986), Buono vd. (1985) gibi araştırmacılar, satın alınan ve satılan işletmelerin kültürel uyumunu ve kombinasyonun başarısı üzerindeki etkisini incelemişlerdir. $\mathrm{Bu}$ araştırmaların çoğu teori oluşturma aşamasında kalmaktadır. Graves (1981), Levinson (1970), Costello vd. (1963) gibi araştırmacılar ise kültürel uyum ve birleşme performansı arasındaki ilişkiyi test eden az sayıda çalışmada, çalışanların motivasyonu ve tutumları gibi parçalanmış bir dizi kriter değişkeni seçmiş ve her seferinde yalnızca bir birleşmede katılımcılara odaklanmıştır. Haspeslagh ve Jemison (1991), Schweiger ve Walsh (1990)'ın çalışmaları kültürel uyumun birleşmelerin kurumsal finansal performansı üzerindeki etkilerini incelememiş̧ir, ancak bazıları olası strateji, kültür ve performans bağlantılarını tartışmıştır. Chatterjee vd. (1992), öz sermaye ile beşerî sermaye arasında güçlü bir bağ bulmuşlardır (Chatterjee vd., 1992:319-320).

Örgütsel davranış okulu, örgütler, örgüt kültürü ve bireyler üzerindeki etkilerini (Birkinshaw vd., 2000; Haspeslagh ve Jemison, 1991) veya kuruluşla ilgili değişkenlerin, örneğin edinim deneyimi (Haleblian ve Finkelstein) üzerindeki etkilerini araştırır. Örgütsel davranış okulu, birleşme sonrası sorunları kültürel uyum veya uyumluluk gibi birleşme sonrası sorunları, örneğin entegrasyon derecesini ele alır. Örgütsel davranış literatüründe öne çıkan araştırmacılardan bazıları Chatterjee vd. (1992), Datta (1991), Appelbaum vd. (2000), Shrivastava (1986) önceleri kültürel uyum konusunda kültürel mesafe, benzerlik ve uyumluluk konuları üzerinde dururlarken, sonraları entegrasyon konusunda, kültürel entegrasyona dikkat çekmişlerdir (Bauer ve Matzler, 2014:270-271).

Literatürde Sørensen (2002), Guiso vd. (2014) gibi araştırmacılar kurumsal kültürün işletmelerin performansını açıklamada önemli bir rol oynayabileceğini göstermişlerdir (Meier vd., 2019:1172). Schneider ve Meyer (1991) bir örgütün sosyokültürel bağlamının da önemli bir rol oynayabildiğine ve ulusal kültürün stratejik meseleleri yorumlama ve yanıtlama üzerindeki etkisine vurgu yapmışlardır. Çalışmalarında ulusal kültürün stratejik konuların yorumlanması ve yanıtlanması üzerindeki etkisini göstermişlerdir (Schneider ve Meyer, 1991:309). 
Geniş strateji literatürü ve özellikle kaynak tabanlı görüş gibi, stratejik insan kaynakları literatürü, kuruluşların benzer rekabet ortamları ve baskılarıyla karşılaştıklarında bile insan kaynakları yönetimi uygulamaları ve örgüt kültürleri açısından kendilerini farklılaştırabilecekleri ve yapabildikleri ve benzersiz olmanın yüksek seviyelerde başarıya ulaşılmasına yardımcı olabileceği varsayımı altında ilerlemiştir (Gerhart, 2009:245). Stratejik hedeflere ulaşımda örgütün kültürü, söz konusu kaynakları harekete geçirmek için kullanılacak teşvikler ve hedeflere ulaşımı kolaylaştıracak destekleyici etkinlikler bir arada olmalı ve her bir faktör arasında koordinasyon ve eşgüdüm bulunmalıdır (Luecke, 2015:79).

Literatürde strateji ile örgüt kültürü arasındaki uyum ve olumlu etkileşimin sağlanmasına yönelik olarak iki farklı yaklaşım bulunmaktadır. Bu yaklaşımlardan ilki "Strateji örgüt kültürünü izlemeli”, ikinci yaklaşım ise tam tersi olarak "Örgüt kültürü stratejiyi izlemeli” yaklaşımıdır. Stratejilerin örgüt yapılarına etkileri ve örgütün yapısal bileşenlerinin strateji ile uyumlu olması gerekliliği stratejik yönetim yazınında tartışıla gelmiştir (Miller, 1986:234). Literatürde genel kabul görmüş görüşe göre, stratejiler örgüt kültürüne uygun seçilmeli ve aralarında çatışma olmamalıdır. Stratejik yönetim, örgütlerin kendi geleceklerini biçimlendirmelerinde daha proaktif olmalarını sağlar, kendi kaderleri üzerinde etki edebilmelerine izin verir (David, 2011:48).

Literatürde, Shin vd. (2012) ve Achtenhagen vd. (2013) çalışan bağlılı̆̆ını sağlamak için güçlü bir kültürün önemini, Bock vd. (2012) yaratıcı bir kültürün kuruluşlar üzerindeki olumlu stratejik esneklik etkisini, Aspara vd. (2013) stratejik dönüşüm veya kurumsal dönüşüm sırasında yöneticilerin stratejik seçimleri üzerine paylaşılan örgütsel bilişlerin güçlü etkisini, kurum kültürünü ve iş modelini değiştirme yeteneğini incelemişlerdir (Hock vd., 2015:434).

Literatürde Chatterjee vd. (1992), Schraeder ve Self (2003), Teerikangas ve Very (2006) gibi araştırmacılar kültürel uyumun, potansiyellerin, sinerjilerin gerçekleşmesi ve başarı üzerinde güçlü bir etkiye sahip olduğunu iddia etmişlerdir (Bauer ve Matzler, 2014:274). Operasyonel stratejiye sahip olmak için gerekli tüm alan, teknolojik ve idari kararlar doğru bir şekilde uyarlanmadıkça, strateji etkili bir rehber değil sadece bir ifade olur (Miles vd., 1978:557). Uyum ne kadar başarılı olursa performansta o kadar iyi olur (Junqueira vd., 2016:336). Brenes vd. (2008), başarılı bir stratejinin uygulanmasını strateji, yap1 ve örgüt kültürü arasındaki uyumla ilişkilendirmişlerdir (Neis vd., 2016:481). Stratejik yönetim süreci içerisinde, stratejik analiz aşamasında örgüt kültürünün çok iyi tanınması ve analiz edilerek değerlendirilmesi gerekmektedir. Alternatif değişim planları arasında seçim yapılırken kültürel uygunluk temel kriter olarak belirlenmeli ve ona göre stratejiler seçilmelidir (Unutkan, 1995:86).

Thompson ve Strickland (1999)'e göre uyumda ne kadar başarı sağlanırsa stratejide o kadar iyi uygulanabilir. Waterman vd.'ne (1980)'e göre etkili strateji uygulaması esasen strateji ve örgüt kültürü gibi çeşitli faktörler ve hedefler arasındaki uyuma dayanır (Okumuş, 2003:871-882). Türk Dil Kurumuna göre uyum; bir bütünün parçaları arasında bulunan uygunluk, ahenk, toplumsal çevreye veya bir duruma uyma, uyum sağlama, intibak ve entegrasyon anlamındadır (http://www.tdk.gov.tr). Stratejik uyum, örgütün durumunun dâhili olarak tutarlı olmasın1 gerektirir (Burton ve Obel, 2004:21).

Brenes vd. (2008), başarılı bir strateji uygulamasının, strateji ve örgüt kültürü arasındaki uyumla ilişkili olduğu görüşündedirler (Neis vd., 2016:480-490). Miles ve Snow (1984) da örgütü, strateji, yapı ve süreçler arasındaki ilişkileri göz önüne alan dinamik bir varlık olarak görmüşlerdir. Park vd. (2011), dâhili ve harici uyum arasındaki farkı belirtmişler ve mikro ve makro uyum terimlerini kullanmışlardır. Örgütün strateji ve yapı ile çevre arasındaki bağlantıların oluşturulması ve sürdürülmesine yönelik örgütler arası bir ilişki olarak makro uyumun ve strateji, yapı ya da kurum içi ilişkiler arasında güçlü bir ilişkinin geliştirilmesi içinde mikro uyumun sağlanması gerekir (Aleksic ve Jelavic, 2017:89).

Hrebiniak (2006)'ın açıkladığı gibi, Homburg vd. (2004) de Chandler'e katılıyorlar ve örgütlerin öncelikle stratejik kararları verdiklerini ve daha sonra örgütsel yapılarını nasıl uyarlayacaklarını analiz ettiklerini açıklamışlardır. Amitabh ve Gupta (2010), yapının başarılı bir stratejinin uygulanmasında temel faktörlerden biri olarak göstermişler ve doğrudan örgüt faaliyetlerini etkilediğini ve yapılandırdığını belirtmişlerdir. Brenes vd. (2008), başarılı bir strateji uygulanmasını, doğrudan strateji, yapı ve örgüt kültürü arasındaki uyumla ilişkilendirmişlerdir. Hussey (1996) ve Hrebiniak (2006) ise, yapının strateji ile uyumlu olması gerekliliği ile birlikte, bilgi paylaşımı ve her üyenin sorumluluğunu açıkça tanımlaması gerekliliğine dikkat çekmişlerdir. Kich ve Pereira (2011)'a göre ortaya çıkan süreçler stratejileri etkilemektedir (Neis vd., 2016:481).

Hamel ve Prahalad, uyum konusunda, örgütteki tutkunun azalmasına yol açılması durumunda, amaçlara ulaşma konusunda, yarardan çok zarar vereceğini söylemişler ve bu nedenle seçilen stratejiler, işletmenin bulunduğu yer ile bulunmak istediği yer arasında uyumsuzluk yaratmamalıdır (Hamel ve Prahalad, 1996:147). Çevresel firsatlara uyan bir strateji, yalnızca düzgün ve etkili bir şekilde uygulandığında üstün performans gösterebilir. 
Stratejik uyum perspektifinden bir strateji uygulamasının odağındaki bir stratejide yapı (Chandler, 1961), yönetim sistemleri (King, 1978) ve örgüt kültürü (Schwartz ve Davis, 1981; Stonich, 1982) gibi değişkenlerle doğru bir şekilde eşleştirilmesi gerekir. Venkatraman ve Camillus (1984)'e göre bu perspektifin altında yatan varsayımı, stratejinin en üstten gelen konsept olduğu ve uygulama unsurlarının verilen stratejinin bağlamından türetildiğidir (Xu vd., 2006:5). Bartlett ve Ghoshal, uyum için, paylaşlan değerler ve enformel ağlara dikkat çekmişlerdir (Wolf ve Egelhoff, 2001:137).

\section{ISSETMELERDE STRATEJIK YÖNETIM ARACI OLARAK ÖRGÜT KÜLTÜRÜ}

Stratejik yönetim süreçleri örgüt kültürüne önemli derecede bağımlıdır (Turunç, 2013:325). Coyne (1986) sürdürülebilir rekabet avantajının kaynaklarını dört çeşit kapasite ayrımı olarak; fonksiyonel ayrım, konumsal ayrım, kültürel ayrım ve düzenleyici ayrım olarak tanımlamıştır (Hall, 1992:136). Güç, kültür, çevre ve yapılandırma okulları strateji biçimlendirme süreçlerine vurgu yapmışlardır (Betz, 2010:208). Kaynak tabanlı görüşe göre, örgütlerin sürdürebilir rekabet avantajı sağlamasında örgütlerin sahip olmuş oldukları kaynaklar çok önemli ve etkilidir. Örgütün kaynaklarının değeri, onların nadir, sınırlı ve taklit edilmesinin zor olmasından gelir. Barney, örgütün sahip olduğu insan kaynağının örgüte temel rekabet avantaj1 getireceğini savunmuştur (Barney, 1991:105). Barney ve Wright (1998:43), kaynak tabanlı görüşün çerçevesinin önemli bir sonucunun beşerî sermaye becerileri, çalışan bağlılığı, kültür, ekip çalışması gibi insan kaynakları işlevlerinin, sürdürülebilir rekabet avantajının kaynağı olmasını muhtemel görmüşlerdir. Lawler (2003:35) ise, insanların, yapıların, ödüllerin ve süreçlerin örgütsel tasarım unsurlarının kurum kültürüne yol açtığını belirtmiştir (Gerhart, 2008:245).

Kaynak temelli görüş, sürdürülebilir kültür avantajının bir yolu olarak örgüt kültürünü farklılaştırmanın potansiyel önemini vurgulamıştır. Aksine bağlamsal görüş ise, örgütsel kültürün büyük ölçüde çevre tarafından belirlendiğini ve ulusal kültür gibi kurumsal güçleri vurguladığını savunmuştur. Gerhart (2009)'in kavramsal analizi ve ampirik kanıtların yeniden analizi, ulusal kültürün ortalama olarak örgüt kültürü üzerindeki bir kısıtlama olarak varsayılan güçlü rolünü desteklememiştir. Bu nedenle, kuruluşlar, kurumsal kültürü ve ilgili yönetim uygulamalarını yerelleştirmeyi ya da standartlaştırmayı seçerken, geleneksel bilgeliğin önerdiğinden daha fazla takdir hakkına sahip olabilirler. Ulusal kültürün örgüt kültürünü ne zaman kısıtladığııı ve bunun ne zaman daha az olası olduğunu belirlemek için gelecekteki araştırmalara ihtiyaç vardır (Gerhart, 2008:255).

Örgütün tamamlayıcı elemanlarının uygunluğu (politik, teknik ve kültürel sistem) ve bunların stratejik konusunun tamamlayıcılarıyla (strateji, yapı ve insan kaynakları) bütünleştirilmesi, örgütün başarısı için çok önemlidir (Tichy, 1983:65-66). Kluckhohn ve Strodtbeck (1961) ve Schein (1985) gibi araştırmacılara göre kültürel değerler, çevrenin yönetimsel görüşlerinin ve uygun örgütsel tepkilerin şekillendirilmesinde merkezi bir rol oynamaktadır. Sonuç olarak, Hambrick ve Brandon (1988) ve Schneider (1989) göre de kültürel değerler strateji oluşturma sürecini ve sonuçlarını etkilemeleri beklenmektedir (Geletkanycz, 1997:616).

Hall (1992) makalesinde hem teorik akıl yürütme hem de ampirik kanıtlar yoluyla, örgüt kültürü gibi maddi olmayan kaynakların analizinin stratejik yönetim sürecinde önemli bir rol oynaması gerektiğini savunmuştur (Hall, 1992:135). Russo vd. (2013) çalışmalarında yönetimin stratejilerini, politikalarını ve uygulamalarını örgüt kültürleriyle uyumlaştırılmasının, örgüt kültürü içinde ortak vizyonlar geliştirmek için bir teşvik görevi gördüğünü ifade etmişlerdir (Russo vd., 2013:13).

Ortak bir örgüt kültürü yaratılmasında, örgüt üyelerinin ortak bir vizyona sahip olmaları ve vizyona inanılmas1 önem arz eder. Ortak bir kültüre sahip örgütler, ortak davranış, inanç, değerler ve ortak beklentilere sahip olacaktır (Daniels ve Daniels, 1994:109). Örgütün üyeleri arasında paylaşılan inanç ve değerler, o örgüt içinde ki eylem ve düşünceleri etkiler (Pearce ve Robinson, 2015:340). Örgütsel kimlik kavramı ile işyerinde ki çalışanların birçok davranış ve tutumunu açıklama ve yorumlama imkânı vardır. Örgütsel kimliğin oluşması, birey ve örgütün amaçlarını bütünleştirerek bireyin ve örgütün bu amaçlar için daha çok çalışmasına olanak sağlamaktadır (Edward, 2005:208).

Fayolle vd. (2010) tarafından örgüt kültürünün küçük bir işletmenin girişimci yönlendirmesi ve performansının itici gücü olabileceği öne sürülmüştür. Dwyer vd. (2003)'ün temel varsayımı, örgütsel kültürün firsat tanıma dinamiklerinde anahtar bileşenler olan yaratıcı davranışları teşvik edebileceğidir. Barney (1986), Sørensen ve Sorensen (2002), Fayolle vd. (2010) örgüt kültürü ile küçük işletme girişimci yönelimi ve performans arasında pozitif bir ilişki olduğunu varsaymışlardır (Khedhaouria vd., 2020:1-2).

Argyris ve Schön (1978), Kabanoff ve Daly (2002), Siehl ve Martin (1990), Sutton ve Callahan (1987) gibi araştırmacılara göre, örgüt kültürü içinde tutarlı olan benimsenen değerler, bir kuruluşun itibarını güçlendirir ve dış meşruiyet sağlar (Craft, 2018:142). Dennison (1990), Covin ve Slevin (1988), Covin (1985) gibi 
araştırmacılar üst yönetim ekibinin kültürü ile işletmenin finansal performansı arasında anlamlı bir ilişki bulan, birleşmemiş bir bağlamda yapılan bir dizi çalışma ile kanıtlanmışlardır (Chatterjee vd., 1992:321).

Bir örgütün ritüelleri, öyküleri ve sembolleri buzdağının yalnızca görünen kısmıdır. İnançlar, değerler, tutumlar ve temel varsayımlar gizli ama belirleyicidir. Güçlü kültürler, personele bir aidiyet hissi verir ve bu da iş tatmini veya personelin kaybedilmemesi gibi faydalar sağlar (Marcouse vd., 2014:108). Misyon, örgüt işlevlerinin iş birliği içinde yerine getirilmesinde kültürel bir birleştiricidir ve işletmedeki tüm çalışanlara ortak bir istikamet verir (Donelly vd., 1984:131).

İşletmenin amaçladığı strateji yapı, sistemler ve kurumsal kültür aracılığıyla uygulanır (Grant ve Jordan, 2014:414). Bir işletmenin örgüt kültürü, stratejik yönetimin daha kolay bir şekilde uygulanmasına katkıda bulunabilir. İşletme kültürü, işletme stratejisini de destekleyen önemli bir faktördür (Pamuk vd., 1997:267). Deal ve Kennedy (1982), Wilkins ve Ouchi (1983)'e göre örgüt kültürü verimliliği artırmak için bir araç olarak kullanılabilir ve tüm çalışanları organizasyon hedeflerine katılmaya teşvik etmek için kullanılabilir (AppiahAdu ve Blankson, 1998:241).

Hynes (2009)'a göre örgüt kültürü işletme performansını doğrudan etkilemeyebilir, ancak işletmenin girişimci yönlendirmesi aracılığıyla strateji oluşturma süreçlerini etkileyebilir ve bu da işletmenin performansını etkileyebilir. Khedhaouria vd. (2020)'nin araştırma sonuçları küçük bir işletmenin bir adhokrasi kültürü ve bir piyasa kültürü ile karakterize edilen örgüt kültürünün finansal performansı artırmak için gerekli yenilikçi ve proaktif davranışları teşvik edebileceğini göstermektedir (Khedhaouria vd., 2020:2).

Kültür yapısı, sistemleri ve çalışanları stratejisi için tamamen uygun olan hiçbir örgüt yoktur (Davis, 1982:68). Strateji uygulayıcıları, stratejiyi destekleyici örgütsel iklimi ve kültürü teşvik etmek zorundadır (Thompson ve Strickland, 1984:268). İşletmelerin faaliyet gösterdiği yapısal koşulları, kaynakları, yetenekleri ve stratejik zihniyeti doğru stratejik yaklaşımı seçmelerinde belirleyicidir (Kim ve Mauborgne, 2009:73).

Stratejiler oluşturulurken göz önüne alınması gereken araçlar olarak; çeşitlilik derecesi, büyüme, değişim hızı ve mevcut kültürü gibi faktörlere bağlı olduğu söylenebilir (Bourgeois ve Brodwin, 1984:260). Stratejileri başarılı bir şekilde uygulayabilmek ve stratejik açıdan örgütleyebilmek için işletmeyi bir kültür sistemi olarak dikkate almak, uyum ve iş birliği içerisinde harekete geçirmek gerekir (Dinçer, 2013:310).

Yöneticiler, stratejik bir zihniyet için, stratejinin, herkesin işi olduğuna dair ortak bir inanç oluşturulmalı. Bu stratejik olarak düşünmek anlamına gelir ve belirli bir kültür, bir dizi ortak değer ve kabul edilen davranış gerektirir (Fogg, 2012:80). İşletmelerde karar vericilerin kalite yönetimi uygulamalarını etkin bir şekilde uygulayabilmeleri için, örgüt kültürü ve bu kalite uygulamaları arasındaki etkileşimi anlamaları gerekmektedir. Leung vd.'ne (2005) göre uluslararası bağlam potansiyel olarak "örgütsel üyelerin" değer ve inançlarına ve dolayısıyla örgütsel kültüre neden olabilir. Dolayısıyla örgüt kültürü, kalite yönetimi uygulamaları ve performans arasındaki ilişkiyi incelerken uluslararası bağlamı açıklamak önemlidir (Naor vd., 2008:672).

Strateji, işletmenin kültür ve değerlerine uygun rasyonel hedeflerin tanımlanması ve sürdürülmesine imkân sağlar (Teece, 2013:254). Bir işletmenin kültürü ve stratejisi ile birlikte dinamik ve tamamlayıcı kaynakları olan insan sermayesini çevresel koşullar altında yönetme kabiliyeti geliştirilmelidir (Chan vd., 2004:18-19). Misyon, örgüt işlevlerinin iş birliği içinde yerine getirilmesinde kültürel bir birleştiricidir (Yurtsever, 1998:26). Örgüt geliştirme, örgüt üyeleri tarafından paylaşılan değerleri ve normları değiştirme ve geliştirmeye çalışarak örgüt kültürü yönetimine hizmet eder (Unutkan, 1995:102). Örgüt üyelerinin örgüt kültürünü tanımalarına, ideal örgüt kültürünün oluşması için yapılan planlamaya ve örgütün gelişmesine destek olunması beklenir (Efil, 2010:132).

Graham vd. (2017) örgüt kültürünün rolünü incelediler ve 1.348 Kuzey Amerika firmasının kıdemli yöneticiler ile yapılan görüşmelere dayanarak başarıya ulaşma konusuyla ilgili soruya bir yanıt sundular. Bu çalışmanın sonuçları, katılımcıların \%92'sinin kültürlerini geliştirmenin işletmelerin değerini artıracağına inandığını; \%85'i etkisiz bir kültürün (yani, kültürel değerler ve normlar arasındaki bağlantıdan yoksun) bir çalışanın etik dışı veya hatta yasadışı olarak hareket etme şansını artırdığına inanmaktadır. Bu sonuçlar göz önüne alındığında, üst düzey yöneticilerin kültürü etik seçimler, yenilikçilik (yaratıcılık ve uygun risk alma) ve değer yaratma ile ilişkilendirmeleri şaşırtıcı değildir (Smimou, 2020:360).

\section{SONUC}

Çalışmamızda işletmelerde strateji uygulamalarının örgüt kültürü üzerindeki etkileri, işletme stratejilerinin belirlenmesi ve uygulamalarına olan etkisi ile bu etkinin önemi üzerine yapılan yazındaki tartışmalar ortaya konulmuştur. İşletmelerde stratejik yönetim süreci uygulamalarının örgüt kültürü üzerindeki karşl1ıklı etkileri 
Uluslararası Yönetim Akademisi Dergisi, 2020, C.3, S.1, ss.138-151 olduğu ve uyumun önemi konularının yazında özellikle vurgulandığı tespit edilmiştir. Tüm örgütçe kabul edilen ortak bir örgüt kültürü oluşturmak, işletme performansına olumlu katkı sağlar. Güçlü örgüt kültürü, çalışanlara kurumsal kimlik kazandırır, ortak sahiplenmeyi kolaylaştırır, takım gibi hareket etmelerini sağlar. Güçlü kültüre sahip örgütler daha başarılı olurlar. Güçlü bir örgüt kültürünün oluşturula bilinmesi için, örgüt üyelerinin aynı doğrultuda ortak değer, norm ve inançları benimsemeleri sağlanmalıdır.

Hiçbir örgüt mevcut kültürünü yok sayarak veya göz ardı ederek hedeflerine ulaşamaz. Literatürde stratejilere uygun örgütsel yapının ve örgüt kültürünün oluşturulmasının önemli bir kritik başarı faktörlü olduğu görüşlerinin ağırlıklı olarak ortaya konulduğu tespit edilmiştir. Literatürde Choo (2013:775), Aspara vd. (2013), Wiewiora vd. (2013) gibi araştırmacılar, örgütsel kültürün örgütsel davranışın birçok yönünü etkilediği tespit etmişlerdir. Gregory vd. (2009) gibi araştırmacıların örgüt kültürünün işletme davranışları ve kurumların etkinliği üzerinde önemli bir etkisi olduğu fikri, yönetim araştırmasında yeni değildir. Gregory vd. (2009) örgütsel kültürün çalışanların tutumları ve kurumun genel etkinliği konusundaki etkilerini göstermişlerdir (Hock vd., 2015:436). Hambrick ve Mason (1984), Hambrick ve Brandon (1988), Schneider (1989) gibi araştırmacılar kültürel değerlerin üst düzey yöneticilerin organizasyon liderleri ve stratejik karar vericiler olarak rollerine getirdikleri yönelimleri şekillendirmeye yardımcı olduğu görüşünü desteklemek için zorlayıcı kanıtlar sunmuşlardır (Geletkanycz, 1997:629).

Yönetim uygulamaları ve stratejisinin örgüt kültürünü etkilemesi beklenmektedir (Gerhart, 2009:247-248). Bauer ve Matzler (2014), yaptıkları araştırma sonucunda, stratejik tamamlayıcıllı̆ın kültürel uyumu ve entegrasyon derecesini de olumlu yönde etkilediği sonucuna varmışlardır. Kültürel uyum, birleşme ve satın alma başarısını olumlu etkilemektedir (Bauer ve Matzler, 2014:269). Schneider ve Meyer (1991), stratejik meseleleri yorumlamada ve bunlara yanıt vermede kültürel farklılıklar bulunduğunu belirtmişlerdir. Araştırmalarında çevresel bağlamın etkisini, yani ulusal kültürün etkisini inceleyerek, bireysel, grup ve örgütsel özelliklerin stratejik meseleleri yorumlama ve yanıtlama üzerindeki etkisini gösteren geçmiş araştırmalara dayandırmışlardır (Schneider ve Meyer, 1991:315-318). Uzun vadeyi planlayan yöneticiler, yüksek performansı teşvik eden uygulamaların uygulanması ile profesyonellerinin kültürel uyumunu sağlamak için örgüt kültürünü tanımlamalidırlar (Russo vd., 2013:19).

Literatürde işletmelerde stratejik yönetim uygulamalarının örgüt kültürü, örgüt yapısı ve insan kaynakları yönetimini ile uyumunun öneminin çoğunlukla vurgulandığı tespit edilmiştir. Literatürde taraması sonucunda Bauer ve Matzler (2014) gibi araştırmacılar ile birlikte Bijlsma-Frankema (2004), Bragado (1992), Jemison ve Sitkin (1986) gibi araştırmacılarında daha yüksek kültürel uyum ile daha hızlı bir entegrasyonun mümkün olduğunu savundukları tespit edilmiştir (Bauer ve Matzler, 2014:274). Eren vd. (2000) Türkiye'nin 100 büyük işletmesinde yapmış oldukları araştırmada, örgüt kültürünün, önemli bir örgüt içi unsuru olarak stratejik yönetime katkıda bulunduğunu tespit etmişlerdir. Önemli ölçüde güç ve kuvvet unsuru olan örgütün yaşı, örgüt kültürü, örgüt yapısının durumu, örgütün büyüklüğü gibi hususlar ile stratejik amaçlar arasındaki uyumun katkısını ortaya çıkarmışlardır (Eren vd., 2000:117).

Stratejik yönetim süreci uygulamalarında, örgüt kültürünün önemi, etkisi ve karşılıklı etkileşimi yadsınamaz. Seçilen ve uygulanan stratejiler, örgüt kültürü ile çelişmemelidir. Bu süreç doğru yönetilirse, işletme performansına ve işletme hedeflerinin gerçekleştirilmesine olumlu katkı sağlar. Ortak değerlere ve bilince sahip yüksek kültürlü örgütler üstün performans gösterirler. Örgüt kültürü örgütün DNA’sıdır. Örgütü oluşturan tüm unsurların; çalışanlar, prosedürler, süreçler, kültür ve teknoloji gibi yapı ve strateji üzerinde etkisi vardır. Hock vd. (2015), Aspara vd. (2013) ve Martins vd. (2015) çalışmaları örgütsel kültürün iş modeli inovasyon yetenekleri üzerinde bir etkiye sahip olduğunu ampirik olarak desteklemiştir (Hock vd., 2015:443).

Literatür taraması sonucunda mevcut tartışmalar çerçevesinde, örgüt kültürünün stratejiler üzerinde ve stratejilerinde örgüt kültürü üzerinde kaçınılmaz etkileri olduğu konusunda tartışmalar olduğu tespit edilmiştir. Özellikle strateji ve kültür arasında karşılıklı uyum ve etkileşimin olumlu etkileri üzerinde vurgu yapıldığ 1 görülmektedir. Örgüt kültürü işletmelerin belirlenen hedeflere ulaşmalarında olumlu veya olumsuz önemli bir rol oynar. Stratejik yönetim literatüründe strateji-örgüt kültürü uyumunun sıklıkla gündeme geldiği ve tartışma konusu olduğu görülmüştür. Örgüt kültürünün stratejiler üzerinde önemli etkileri vardır. Bu nedenle örgüt kültürünün unsurları ve mekanizmalarının stratejiler ile uyumlu olması gerekliliği stratejik yönetim yazınında tartışıla gelmiştir. Literatürde strateji ve örgüt kültürü arasında bir uyumun gerekliliğinden bahsedilmesine rağmen yazın bu uyumun mekanizmalarını netleştiremediği tespit edilmiştir. Oysa bu mekanizmaların netleşmesi uyumun sağlanması açısından hayati önem arz etmektedir.

Literatür taraması sonucunda, örgütsel kültürün stratejik konuları etkileyeceğinin tartışıldığı tespit edilmiştir. Örgütsel kültür işletmeden işletmeye farklılık arz edeceğinden hem iç hem de diş 'firsat' ve 'tehdit' yorumlarını 
etkileyecektir. Çevresel olayların farklı şekillerde yorumlanması ve bu farklılıkları anlamak, rakiplerle yüzleşmede rekabet avantajı sağlayabilir.

Literatürde örgüt kültürünün stratejiye göre uyumlu olması veya stratejinin örgüt kültürüne uyumlu hale getirilmesi şeklinde iki farklı yaklaşım konusunda tartışmalar olduğu tespit edilmiştir. Stratejik yönetim sürecinde örgüt kültürünün önemli bir etkisinin olduğu ve işletmelerin başarısında önemli bir etkiye ve karşıllklı etkileşime sahip olduğu kabul edilmektedir. Literatürdeki çalışmalarda kültürün önemi ve kültürel özelliklerin çoğunlukla vurgulandığı tespit edilmiştir. Ancak örgütsel kültür ile operasyon yönetimi uygulamaları ve performans arasındaki bağın daha fazla incelenmesi literatüre farklı katkılar sağlayacak ve uygulayıcılara yön gösterecektir.

Strateji ve örgüt kültürü ilişkisi ve etkileşimi konularında uygulamaya yönelik araştırmaların artırılması işletmelere strateji seçiminde 1şık tutarak, gelecek için öngörü oluşturarak gelişmelerine katkı sağlayacaktır. Gelecekte strateji ile örgüt kültürünün uyumu konusunda özellikle örgütsel kimlik, iklimin önemi ve uygulamada stratejik bir araç olarak kullanımından örneklere yönelik araştırmaların yapılması, sorunları tespit etmek ve önerilerde bulunmak açısından faydalı olacaktır. İşletmelere rehberlik etmek ve gelecek için öngörü oluşturmak açısından strateji ile örgüt kültürü uyumu konusunda daha fazla uygulamaya yönelik araştırma yapılmasına ihtiyaç olduğu düşünülmektedir. Özellikle uygulamadan örnekler ile entegrasyon türlerine dayalı bir kavramsallaştırma kullanarak strateji, kültür, performans bağlantısını araştırmak faydalı olacaktır.

\section{KAYNAKÇA}

AKGEMCİ, Tahir ve GÜLEŞ, Hasan Kürşad (2010), İşletmelerde Stratejik Yönetim, Gazi Kitapevi, Ankara, 2. Bask1.

ALEKSIC, Ana ve JELAVIC, Sanda Rasic (2017), "Testing for Strategy-Structure Fit and Its Importance for Performance", Management, S.22, ss.85-102.

APPIAH-ADU, Kwaku ve BLANKSON, Charles (1998), "Business Strategy, Organizational Culture, and Market Orientation", Thunderbird International Business Review, S.40(3), ss.235-256.

BARCA, Mehmet (2005), "Stratejik Yönetim Düşüncesinin Evrimi: Bilimsel Bir Disiplin Oluşum Hikayesi”, Yönetim Araştırmaları Dergisi, S.5(1), ss.7-38.

BARCA, Mehmet (2009), “Stratejik Yönetim Düşüncesinin Gelişimi”, Ankara Sanayi Odasi, S.2, ss.34-52.

BARNEY, Jay B. (1991), “Firm Resources and Sustained Competitive Advantage”, Journal of Management, S.17(1), ss.99-120.

BAUER, Florian ve MATZLER, Kurt (2014), "Antecedents of M\&A Success: The Role of Strategic Complementarity, Culturalfit, and Degree and Speed of Integration", Strategic Management Journal, S.35(2), ss.269-291.

BETZ, Frederick (2010), Yönetim Stratejisi (Çev. Ümit Şensoy), Tübitak Popüler Bilim Kitapları, Ankara.

BOURGEOIS, Jay L. ve BRODWIN, David R. (1984), "Strategic Implementation: Five Approaches to an Elusive Phenomenon", Strategic Management Journal, S.5(3), ss.241-264.

BURTON, Richard M. ve OBEL, Borge (2004), Strategic Organizational Diagnosis and Design: The Dynamics of Fit, Springer Science HBusiness Media, New York, 3. Edition.

CHAN, Lismen M., SHAFFER, Margaret A. ve SNAPE, Ed (2004), "in Search of Sustained Competitive Advantage: The Impact of Organizational Culture, Competitive Strategy And Human Resource Management Practices On Firm Performance", International Journal of Human Resource Management, S.15(1), ss.17-35.

CHATTERJEE, Sayan, LUBATKIN, Michael H., SCHWEIGER, David M. ve WEBER, Yaakov (1992), "Cultural Differences and Shareholder Value in Related Mergers: Linking Equity and Human Capital", Strategic Management Journal, S.13(5), ss.319-334.

CLAYTON, Susan (2002), Takımınızın Yeteneklerini Geliştirmede Strateji Geliştirme (Çev. Mehmet Zaman), Hayat Yayınları, İstanbul. 
CORTES, Claver E., ORTEGA, Eva M. Pertusa ve AZORIN, Molina J. F. (2012), "Characteristics of Organizational Structure Relating to Hybrid Competitive Strategy: Implications for Performance", Journal of Business Research, S.65(7), ss.993-1002.

CRAFT, Jana L. (2018), “Common Thread: The Impact of Mission on Ethical Business Culture, A Case Study", Journal of Business Ethics, S.149(1), ss.127-145.

DAFT, Richard L. (2004), Organization Theory and Design, Thompson South-Wetern, Vanderbilt University, 8. Edition.

DANIELS, John L. ve DANIELS, Caroline N. (1994), Global Vision, McGraw-Hill Inc, Singapore.

DAVID, Fred R. (2011), Strategic Management Concepts, Pearson Education, New Jersey, 13. Edition.

DAVIS, Stanley M. (1982), "Transforming Organizations: The Key to Strategy Is Context", Organizational Dynamics, Winter, ss.64-80.

DİNÇER, Ömer (2013), Stratejik Yönetim ve İşletme Politikası, Alfa Yayım, İstanbul, 9. Baskı.

DONELLY, James H., GIBSON, James L. ve IVANCEVICH, John M. (1984), Fundamental of Management, Business Pub. Inc., Texas, 5. Edition.

DURSUN, İbrahih Taha (2013), “Örgüt Kültürü ve Strateji İlişkisi: Hofstede’nin Boyutları Açısından Bir Değerlendirme", Siyaset, Ekonomi ve Yönetim Araştırmaları Dergisi, S.1(4), ss.43-56.

EDWARD, Martin R. (2005), "Organizational Identification: A Conceptual and Operational Review", International Journal of Management Reviews, S.7(4), ss.207-230.

EFIL, İsmail (2010), Toplam Kalite Yönetimi, Dora Basım Yayın, Bursa, 7. Bask1.

EKŞİ, Hülya (2009), "Stratejik Yönetim ve Örgüt Kültürü: İlişkisel Bir Analiz”, Dumlupınar Üniversitesi Sosyal Bilimler Dergisi, S.24, ss.165-173.

EREN, Erol, AREN, Selim ve ALPKAN, Lütfihak (2000), “işletmelerde Stratejik Yönetim Düşüncesini Değerlendirme Araştırması”, Doğuş Üniversitesi Dergisi, S.1(1), ss.96-123.

FOGG, Davis C. (2012), Stratejiyi Uygulamak (Çev. Melis İnan), Pocket Mentor, Harvard Business School Press, Optimist Yayınları, İstanbul, 2. Bask1.

FONFARA, Krzysztof, MROZEK, Milena Ratajczak ve LESZCZYNSKI, Grzegorz (2018), "Change in Business Relationships and Networks: Concepts and Business Reality", Industrial Marketing Management, S.78, ss.1-4.

GELETKANYCZ, Marta A. (1997), "The Salience of Cultures Consequences: The Effects of Cultural Values on Top Executive Commitment to the Status Quo", Strategic Management Journal, S.18(8), ss.615-634.

GERHART, Barry (2009), "How Much Does National Culture Constrain Organizational Culture?", Management and Organization Review, S.5(2), ss.241-259.

GRANT, Robert B. ve JORDAN, Judith (2014), Stratejinin Temelleri (Çev. Gamze Sart), Nobel Akademik Yayıncilık, Ankara.

GREENBERG, Jerald (2002), Managing Behavior in Organizations, Prentice Hall, 3. Edition.

GOVER, Laura, HALINSKI, Michael ve DUXBURY, Linda (2016), "Is it Just Me? Exploring Perceptions of Organizational Culture Change", British Journal of Management, S.27(3), ss.567-582.

GULATI, Ranjay, NOHRIA, Nitin ve ZAHEER, Akbar (2000), "Strategic Networks", Strategic Management Journal, S.21(3), ss.203-215.

HODGETTS, Richard M. (1997), Yönetim (Çev. Canan Çetin - Esin Can Mutlu), Der Yayınları, İstanbul, 5. Bask1.

HALL, David J. ve SAIAS, Maurice A. (1980), "Strategy Follows Structure”, Strategic Management Journal, S.1(2), ss.149-163.

HALL, Richard (1992), "The Strategic Analysis of Intangible Resources", Strategic Management Journal, S.13(2), ss.135-144.

HAMEL, Gary ve PRAHALAD, Coimbatore Krishnao (1996), Competing for The Future, Harvard Business School Press, Boston. 
HILL, Charles W. L., JONES, Gareth R. ve SCHILLING, Melissa A. (2013), Strategic Management Theory, Cengage Learning, Canada, 11. Edition.

HITTMAR, Stefan ve JANKAL, Radoslav (2015), "Strategic Management of Networks", Management of Network Organizations, Springer, ss.5-22. (e-book: Sroka Wlodzimierz, Hittmar Stefan, Management of Network Organizations, Springer, 2015).

HOCK, Marianne, CLAUSS, Thomas ve SCHULZ, Esther (2015), "The Impact of Organizational Culture on a Firm's Capabililty to Innovate the Business Model", R\&D Management, S.46(3), ss.433-450.

JHONSON, Gerry ve SCHOLES, Kevan (1999), Exploring Corporate Strategy, Prentice Hall Europe.

JUNQUEIRA, Emanuel, DUTRA, Eduardo Vieira, FILHO, Helio Zanquetto ve GONZAGA, Rosimeire Pimentel (2016), "The Effect of Strategic Choices and Management Control Systems on Organizational Performance", Revista Contabilidade \& Finanças, Scientific Electronic Library Online, S.27(72), ss.334-348.

KHEDHAOURIA, Anis, NAKARA, Walid A., GHARBI, Samiha ve BAHRI, Chaima (2020), "The Relationship Between Organizational Culture and Small-firm Performance: Entrepreneurial Orientation as Mediator", European Management Review, January, ss.1-14.

KIM, Chan W. ve MAUBORGNE, Renee (2009), "How Strategy Shapes Structure", Harvard Business Review, S.87(9), ss.72-80.

LUECKE, Richard (2015), Strateji (Çev.Turan Parlak), Harvard Business Press - İş Bankası Kültür Yayınları, İstanbul, 3. Bask1.

LYNCH, Susan ve MORS, Louise (2018), "Strategy Implementation and Organizational Change: How Formal Reorganization Affects Professional Networks", Long Range Planning, February, ss.1-16.

MACIARIELLO, Joseph ve DRUCKER, Peter (2005), Gün Gün Drucker (Çev. Murat Çetinbakış, Zülfü Dicleli), MESS Yayınları, İstanbul.

MARCOUSE, Ian, ANDERSON, Philippa, BLACK, Alexandra, MACHIN, Denry ve WATSON, Nigel (2014), İşletme Kitabı (Çev. Tufan Göbekçin), Alfa Yayınları, İstanbul.

MEIER, Stephan, STEPHENSON, Matthew ve PERKOWSKI, Patryk (2019), "Culture of Trust and Division of Labor in Nonhierarchical Teams", Strategic Management Journal, S.40(8), ss.1071-1193.

MILES, Raymond E., SNOW, Charles C. ve COLEMAN, Henry J. (1978), "Organizational Strategy, Structure, and Process", Academy of Management Review, S.3(3), ss.546-562.

MILLER, Danny (1986), "Configurations of Strategy and Structure: Towards a Synthesis", Strategic Management Journal, S.7(3), ss.233-249.

MILLER, Danny (1996), “Configurations Revisited”, Strategic Management Journal, S.17(7), ss.505-512.

MONDY, Wayne R. ve GORDON, Judith R. (1990), Management and Organizational Behavior, Allyn and Bacon, USA.

MORGAN, Gareth (1998), Yönetim ve Örgüt Teorilerinde Metafor (Çev. Gündüz Bulut), Mess Yayınları, İstanbul.

NAOR, Michael, GOLDSTEIN, Susan M., LINDERMAN, Kevin W. ve SCHROEDER, Roger G. (2008), "The Role of Culture as Driver of Quality Management and Performance: Infrastructure Versus Core Quality Practices", Decision Sciences, S.39(4), ss.671-702.

NEIS, Dyogo Felype, PEREIRA, Mauricio Fernandes ve MACCARI, Emerson Antonio (2016), "Strategic Planning Process and Organizational Structure: Impacts, Confluence and Similarities", Brazilian Business Review, S.14(5), ss.479-492.

NEMLİ, Esra (2000), Çevreye Duyarlı İşletmecilik ve Türk Sanayinde Çevre Yönetim Sistemi Uygulamaları, İstanbul Sanayi Odası Çevre Şubesi Yayınları, İstanbul.

OKUMUŞ, Fevzi (2003), “A Framework to Implement Strategies in Organizations”, Management Decision, S.41(9), ss.871-882. 
ÖZDEVECIOĞLU, Mahmut (1995), “Organizasyon Kültürü̈, Stratejik Yönetim ve Liderlik, İz Yayınları, İstanbul, 2. Bask1, ss.120-127.

ÖZKALP, Enver (1999), "Örgütlerde Kültürel Sorunlar ve Örgüt Kültürünün Korunmasında ve Geliştirilmesinde Uygulanabilecek Programlara İlişkin Eskişsehir'de Yapılan Bir Araştırma", Anadolu Üniversitesi İBF Dergisi, S.15(1-2), ss.437-472.

PAMUK, Gündüz, ERKUT, Haluk, AKGÜÇ, Öztin, ÜLENGIN, Burç, ÜLENGİN, Füsun, ALPAY, Yurdakul ve KOŞMA, Hamza (1997), Stratejik Yönetim ve Senaryo Tekniği, İrfan Yayımc1lık, İstanbul.

PEARCE, John A. ve ROBINSON, Richard B. (2015), Stratejik Yönetim (Çev. Mehmet Barca), McGraw-Hill Irwin, Nobel Yayınları, Ankara, 12. Bask1.

PEREZ, Virginia Fernandez, MONTES, Francisco Javier Llorens ve MORALES, Victor Jesus Garcia (2014), "Towards Strategic Flexibility: Social Networks, Climate and Uncertainty", Industrial Management \& Data Systems, S.114(6), ss.858-871.

PRINCE, Melvin, FORR, James, WARDLAW, Jim ve PLUMMER, Joseph (2019), "CEO Archetype Identtty Drives Organization Culture”, Journal of Leadership Studies, S.13(3), ss.62-67.

RUSSO, Giuseppe Maria, TOMEI, Patricia Amelia, LINHARES, Antonia Braga ve SANTOS, Andre Moreira (2013), "Correlation Between Organizational Culture and Compensation Strategies Using Charles Handy's Typology", Performance Improvement, S.52(7), ss.13-21.

SCHEIN, Edgar H. (1984), "Coming to a New Awareness of Organizational Culture”, Sloan Management Review, Winter, S.25(2), ss.3-16.

SCHNEIDER, Susan C. ve MEYER, De A. (1991), "Interpreting and Responding to Strategic Issues: The Impact of National Culture”, Strategic Management Journal, S.12(4), ss.307-320.

SMIMOU, Kamal (2020), “Corporate Culture, Ethical Stimulus, and Managerial Momentum: Theory and Evidence", Business Ethics, S.29(2), ss.360-387.

TEECE, David J. (2013), Dynamic Capabilities \& Strategic Management, Oxford University Press, Oxford.

THOMPSON, Arthur A. ve STRICKLAND, Josephine A. (1984), Strategic Management: Concept and Cases, Business Publications.

THOMPSON, Arthur A., STRICKLAND, Josephine A. ve FULMER, William E. (1984), Readings in Strategic Management, Business Publication, Texas.

THOMPSON, Arthur A. ve STRICKLAND, Josephine A. (1993), Strategic Management Concepts \& Cases, Irvin, Alabama Univ., NewYork, 7. Edition.

TICHY, Noel (1983), “The Essentials of Strategic Change Management”, Journal of Business Strategy, Spring, S.3(4), ss.55-67.

TURUNÇ, Ömer (2013), "Stratejik Yönetim Örgütsel Performansı nasll Etkiler? Kişi-Örgüt Uyumunun Düzenleyici Rolü", 21. Ulusal Yönetim ve Organizasyon Kongresi Bildiriler Kitabı, Nobel Akademi Yayınları, Kütahya.

UNUTKAN, Göksel Ataman (1995), İşletmelerin Yönetimi ve Örgüt Kültürü, Türkmen Kitabevi, İstanbul.

WOLF, Joachim ve EGELHOFF, William G. (2001), "Strategy and Structure: Extending the Theory and Integrating the Research on National And International Firms", Schmalenbach Business Review, April, S.53, ss.117-139.

WRIGHT, Peter L., PRINGLE, Charles D. ve KROLL, Mark J. (1992), Strategic Management, Allyn and Bacon, Massachusetts.

XU, Shichun, ÇAVUŞGIL, Tamer S. ve WHITE, Chris J. (2006), "The Impact of Strategic Fit Among Strategy, Structure and Processes on Multinational Corporation Performance: A Multimethod Assesment", Journal of International Marketing, S.14(2), ss.1-31.

YURTSEVER, Ridvan (1998), "Stratejik Yönetim Sürecinde Misyon Kavramı”, Yönetim, S.9(29), ss.26-33.

http://www.tdk.gov.tr. (Erişim Tarihi: 15.02.2020). 